\title{
OS DETETIVES DE ARTHUR MACHEN: A INVESTIGAÇÃO DO INSÓLITO SOBRENATURAL
}

\author{
Lais de Medeiros Santos (UERJ)
}

Shirley de Souza Gomes Carreira (UERJ)

Recebido em 08 mai 2020. Laís de Medeiros Santos é Mestranda em Estudos Aprovado em 22 jun 2020. Literários do Programa de Pós-Graduação em Letras e Linguística da UERJ e bolsista FAPERJ. Integrante do grupo de pesquisa Poéticas da Diversidade sob a

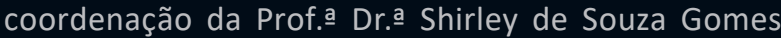
Carreira. Currículo

Lattes: http://lattes.cnpq.br/3570570525953280.

E-mail: laisdemedeirossantos@gmail.com

ORCID iD: https://orcid.org/0000-0001-9172-0086.

Shirley de Souza Gomes Carreira é Doutora em Literatura Comparada, Professora Adjunta 1 da UERJ e docente permanente do Mestrado em Estudos Literários do Programa de Pós-Graduação em Letras e Linguística da UERJ. Líder do grupo de pesquisa Poéticas da Diversidade.

E-mail: shirleysgcarr@gmail.com

ORCID iD: https://orcid.org/0000-0002-8787-8283

Resumo: Na última década do século $\mathrm{XIX}$, quando vários gêneros e vertentes literários coexistiram, Arthur Machen apropriou-se da estrutura da história de detetive, misturando-a a eventos insólitos, em algumas de suas narrativas. O presente artigo tem por objetivo mostrar como esses eventos, presentes 
em quatro textos da fase inicial da carreira do autor, são investigados por personagens que agem como detetives amadores, movidos pela curiosidade e pelo desejo de conhecimento. A análise será feita a partir das perspectivas teóricas de Pykett, Worthington, Kayman, Priestman, Grella e Knight acerca da origem e estrutura das histórias de detetive, bem como de Lytton sobre a presença do insólito em narrativas de crime e investigação.

Palavras-chave: Detetive Amador; Arthur Machen; Insólito.

Abstract: In the last decade of the 19th century, when several genres and literary trends coexisted, Arthur Machen appropriated the structure of the detective story, mixing it with uncommon events, in some of his narratives. This article aims to show how these events, present in four texts from the author's early career, are investigated by characters who act as amateur detectives driven by curiosity and the desire for knowledge. The analysis will be made from the theoretical perspectives of Pykett, Worthington, Kayman, Priestman, Grella and Knight about the origin and structure of detective stories, as well as Lytton's point of view of the unusual in the narratives of crime and investigation.

Keywords: Amateur Detective; Arthur Machen; Uncommon.

\section{A HISTÓRIA DE DETETIVE NA INGLATERRA DO SÉCULO XIX}

O século XIX na Inglaterra foi um período bastante profícuo para a literatura com o surgimento de diversos gêneros literários e o desenvolvimento de meios de produção que facilitaram o comércio de revistas, livros e folhetins. Entre esses gêneros, o romance de Newgate, ou romance de Old Bailey, alcançou grande popularidade. Subgênero da literatura de crime (PYKETT, 2003, 
p.19), que começou a ser produzido por volta de 1830 , o romance Newgate era baseado em casos reais, cuja fonte era o Newgate Calendar, publicado entre o final do século XVIII e o início do século $\mathrm{XIX}$, que continha relatos biográficos de criminosos famosos.

As narrativas do Newgate Calendar circulavam através de panfletos baratos (WORTHINGTON, 2010, p.14) e abordavam a vida e detalhes dos crimes cometidos por prisioneiros na Inglaterra, além das suas confissões, julgamentos e punições severas, o que atraía a atenção do público leitor. As ficções de Newgate, consequentemente, seguiam no mesmo formato das narrativas relatadas no Newgate Calendar, porém, de acordo com alguns críticos da época, elas romantizavam a vida marginal e o crime, pois enfocavam as histórias dos infratores e suas motivações ao invés de se centrarem nas vítimas, produzindo simpatia nos leitores pelo criminoso, retratado como vítima das circunstâncias e da sociedade (PYKETT, 2003, p.20).

No entanto, apesar de ter recebido duras críticas e ter usufruído de popularidade por cerca de duas décadas, o romance de Newgate também foi capaz de exercer "considerável influência sobre a representação do crime no romance do século XIX em geral, e no desenvolvimento de gêneros e subgêneros posteriores, como o romance de sensação e o romance de detetive"1 (PYKETT, 2003, p.19 - tradução nossa). O romance de sensação, considerado um subgênero, foi bastante popular em 1860 e relatos de crimes reais serviam de base para o enredo de algumas obras da época, assim como o foram nas ficções Newgate. Segundo Lynn Pyckett, os

1 "[...] considerable influence on the representation of crime in the nineteenth-century novel in general, and on the development of such later genres and sub-genres as the sensation novel and the detective novel" (PYKETT, 2003, p.20). 
romances de sensação eram "contos da vida moderna que lidavam com choques nervosos, psicológicos, seculares e sociais, e tinham tramas complicadas envolvendo bigamia, adultério, sedução, fraude, falsificação, chantagem, sequestro e, às vezes, assassinato"2 (2003, p.33 - tradução nossa).

Embora possam ter pontos de convergência, há uma grande diferença entre os dois subgêneros mencionados acima: enquanto o romance de Newgate relatava a vida marginalizada, o romance de sensação abordava o lado obscuro da sociedade respeitável. "Os crimes na ficção de sensação eram sociais, pessoais, acreditáveis e não cometidos por uma subclasse criminosa, mas pelos homens e, chocantemente, por mulheres das classes média e alta"3 (WORTHINGTON, 2010, p.23 - tradução nossa).

A criação da New Metropolitan Police, em 1829, modificou a forma como a força policial atuava em Londres. Apesar de existirem apenas para prevenir possíveis crimes nas ruas, os novos agentes usavam capacetes e uniformes que os tornavam identificáveis em meio à grande população da cidade. De acordo com Stephen Thomas Knight, "a ideia era que eles passeariam pela cidade e agiriam como indicadores visíveis do poder do Estado, uma ameaça constante para os malfeitores de que eles seriam apreendidos e punidos"4 (2004, p.30 - tradução nossa).

2 "[...] tales of modern life that dealt in nervous, psychological, secular and social shocks, and had complicated plots involving bigamy, adultery, seduction, fraud, forgery, blackmail, kidnapping and, sometimes, murder" (PYKETT, 2003, p.33).

3 "the crimes in sensation fiction were social, personal, credible, and not committed by a criminal underclass but by the men and, shockingly, women of the middle and upper classes" (WORTHINGTON, 2010, p.23).

4 "the idea was that they would walk about the city and act as visible indicators of the power of the state, a constant threat to wrong-doers that they would be apprehended and punished" (KNIGHT, 2004, p.30). 
O surgimento bem-sucedido dessa primeira base policial londrina possibilitou que, em 1842, houvesse a inauguração da Detective Police, cujo objetivo não seria percorrer as ruas prevenindo crimes, mas sim investigá-los e solucioná-los.

Com a crescente presença da força policial e detetivesca em Londres, a ficção mudou seu enfoque do crime para a investigação, incluindo o policial detetive como personagem importante da trama. "O criminoso não é mais o sujeito da narrativa, mas o objeto da perseguição do detetive, e o fato de o detetive estar do lado da lei faz a leitura sobre crime ser respeitável"5 (WORTHINGTON, 2010, p.21 - tradução nossa). Por conseguinte, no final do século XIX, na Inglaterra, a ficção de crime já era considerada uma forma estabelecida e a figura do detetive havia sofrido modificações, se desvinculando da força policial e passando a ser representada nas narrativas como um investigador amador.

Apesar de investigadores amadores terem surgido na literatura por volta de 1830, eles não agiam como detetives e sim como reguladores da ordem e disciplinadores de má-conduta. Dessa forma, consideramos que a imagem do detetive amador, que serviu como modelo para obras posteriores, teve início com C. Auguste Dupin em Os assassinatos da rua Morgue (1841), de Edgar Allan Poe, aclamada como a primeira história detetivesca por ser "estruturada inteiramente em torno das deduções

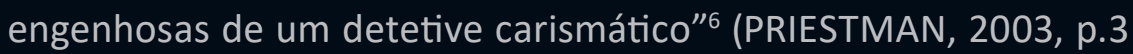
- tradução nossa). Assim, Poe contribuiu para o surgimento de um 5 "The criminal is no longer the subject of the narrative but the object of the detective's pursuit, and the fact that the detective is on the side of the law makes reading about crime respectable" (WORTHINGTON, 2010, p.21).

6 "structured entirely round the ingenious deductions of a charismatic detective" (PRIESTMAN, 2003, p.3). 
novo estilo de narrativa em que os casos são solucionados com análise racional e imaginação:

A combinação de investigação ativa e organização cerebral de Dupin se torna modelo para futuros protagonistas detetives, e é o estabelecimento de padrões narrativos que tornam as histórias do Dupin de Poe um elemento tão importante no desenvolvimento da ficção de crime. $^{7}$ (WORTHINGTON, 2010, p.22 - tradução nossa)

Além de Dupin, muitos outros detetives começaram a surgir na literatura à medida que o gênero ia se desenvolvendo ao longo do século XIX, pois a ficção detetivesca passou a concentrar boa parte de suas narrativas nos grandes centros urbanos, que continuavam a crescer exponencialmente e se tornavam locais sombrios e de possíveis ameaças sociais. Consequentemente, cidades como Londres e Paris, de acordo com Knight, eram vistas como cenários "onde ninguém conhece mais ninguém, onde alguém poderia ser um inimigo, e onde, mais do que nunca, é necessário que algum especialista navegue neste mundo misterioso"8 (2004, p.18 - tradução nossa) a fim de identificar pessoas criminosas e restaurar a ordem social, demonstrando a necessidade do detetive dentro da ficção.

Nesse período surgiram, inclusive, personagens femininas que exerciam o papel de detetives, o que foi bastante revolucionário, dado o fato de que não havia mulheres policiais. Knight afirma 7 "Dupin's combination of active investigation and cerebral organization becomes the model for later detective protagonists and it is the establishment of narrative patterns that makes Poe's Dupin stories such an important element in the development of crime fiction" (WORTHINGTON, 2010, p.22).

8 "where no one knows anybody else, where anyone could be an enemy, and where, more than ever before, there is the need for some expert to navigate this mysterious world" (KNIGHT, 2004, p.18). 
que "A presença dessas detetives mulheres sugere que as editoras sabiam que havia um público feminino substancial para a ficção de crime nessa época - como, é claro, houve para a ficção gótica e, de fato, toda ficção"9 (2004, p.36 - tradução nossa). No entanto, foi graças a Sir Arthur Conan Doyle que o gênero detetivesco se consolidou de fato. Martin Priestman explica que "Com a criação de Doyle da série Sherlock Holmes, a ficção de detetive se tornou, pela primeira vez, um formato de gênero indubitavelmente popular e repetível"10 (2003, p.4 - tradução nossa).

Doyle se inspirou em outros detetives ficcionais como Dupin, Monsieur Lecoq, Ezra Jennings, Ebenezer Gryce e Robert Audley para a elaboração de Sherlock Holmes, um detetive diferenciado que teve sua primeira aparição em Um Estudo em Vermelho (1887) e que rapidamente alcançou sucesso. Na perspectiva de Knight, Holmes é um detetive "altamente inteligente, essencialmente moral, um tanto elitista, onisciente, disciplinar em conhecimentos e habilidades, enérgico, excêntrico, mas também em contato com as pessoas comuns que povoam as histórias"11 (2004, p.55 - tradução nossa).

Ainda de acordo com Knight (2004, p.57), os métodos de investigação de Holmes não são difíceis ou incomuns, o que agradava ao público leitor, que conseguia não só entender a lógica por trás do processo da resolução do crime como também participar imaginativamente nele. Para o teórico,

9 "The presence of these women detectives suggests that publishers knew there was a substantial female audience for crime fiction by this time - as of course there had been for Gothic fiction, and indeed all fiction" (KNIGHT, 2004, p.36).

10 "With Doyle's creation of the Sherlock Holmes series, detective fiction became for the first time an indubitably popular and repeatable genre format" (PRIESTMAN, 2003, p.4).

11 "highly intelligent, essentially moral, somewhat elitist, all-knowing, disciplinary in knowledge and skills, energetic, eccentric, yet also in touch with the ordinary people who populate the stories" (KNIGHT, 2004, p.55). 
Sherlock Holmes e os crimes que ele encontra são ficções: mas as forças imaginativas e ideológicas realizadas nas histórias são reais; nesse sentido, Holmes é um arquétipo da ficção de crime do século inteiro. É através das técnicas de ficção e escrita que esse corpo maciço de literatura foi montado para especular sobre desordem social, ameaças à propriedade e ao corpo, e para imaginar respostas a elas $^{12}$. (2004, p.63 - tradução nossa)

No final do século XIX, a ficção de crime era um gênero consolidado e disseminado na Inglaterra e no exterior (WORTHINGTON, 2010, p.26), e seu principal elemento era o detetive amador. Dessa forma, este trabalho visa a demonstrar como Arthur Machen, autor galês considerado um dos precursores da weird fiction ${ }^{13}$, apropria-se da figura do detetive amador em sua produção literária da última década do século XIX.

\section{OS DETETIVES DE MACHEN - DYSON E VILLIERS}

De acordo com Edward Bulwer Lytton, "o criminoso junto com o sobrenatural é um dos dois principais agentes do terror moral na literatura"14 (1998 Apud PYKETT, 2003, p.19 tradução nossa), e em algumas obras de Arthur Machen esses dois elementos estão unidos, fazendo com que as narrativas apresentem uma característica híbrida, pois ao mesmo tempo em que introduzem o elemento sobrenatural, utilizam recursos

12 "Sherlock Holmes and the crimes he encounters are fictions: but the imaginative and ideological forces realised in the stories are real; in that respect Holmes is an archetype of the whole century's crime fiction. It is through the techniques of fiction and writing that this massive body of literature has been assembled to speculate about social disorder, threats to property and body, and to imagine responses to them" (KNIGHT, 2004, p.63).

13 Subgênero da ficção especulativa que surgiu no final do século XIX (ADLER, 2020, p.2). 14 "The criminal along with the supernatural is one of the two main agencies of moral terror in literature" (LYTTON Apud PYKETT, 2003, p.19). 
narrativos que apontam para a solução de mistérios: a estrutura da história de detetive.

Arthur Machen iniciou sua carreira na Inglaterra do final do século XIX, em meio a muitas vertentes literárias, o que possibilitou ao autor se apropriar de elementos de algumas delas para criar seu próprio estilo de escrita, muito aclamado posteriormente por H.P. Lovecraft em seu livro O horror sobrenatural na literatura (1927). Uma dessas apropriações é a que Machen faz da personagem do detetive amador, presente nas quatro obras selecionadas para esse artigo: A Luz Interior (1894), O Grande Deus Pã (1894), A Mão Vermelha (1895) e A Pirâmide Reluzente (1895).

Para A. E. Murch, a história de detetive é "uma narrativa em que o interesse primário é a descoberta metódica, por meios racionais, da circunstância exata de um misterioso evento ou série de eventos"15 (1958 Apud GRELLA, 1970, p.30 - tradução nossa). Pautada em uma relação de causa e efeito, a ação do detetive visa à resolução do quebra-cabeça. O restante da história prova que a narrativa contada pelo detetive ao final corresponde aos fatos fragmentados que o narrador apresentou objetivamente diante de nós. (KAYMAN, 2003, p.42).

Em Estruturas Narrativas, Todorov (2003) denomina "romance de enigma" as narrativas em que a figura do policial não é essencial, podendo ser ocupada por outras personagens que cumpram este papel. Nas obras de Machen, os detetives são cidadãos comuns que decidem investigar por conta própria os eventos estranhos que acontecem na narrativa, sem que haja envolvimento com 15 "a tale in which the primary interest lies in the methodical discovery, by rational means, of the exact circumstances of a mysterious event or series of events" (MURCH Apud GRELLA, 1970, p.30). 
a força policial ou recompensa monetária por isso, pois a única motivação é o conhecimento e o desejo de descobrir a verdade. A principal personagem desse tipo criada por Machen é Dyson, que aparece em A Luz Interior (1894), A Mão Vermelha (1895) e A Pirâmide Reluzente (1895). No século dezenove, a serialização, ou seja, a técnica de construir diferentes histórias girando em torno de um mesmo detetive, era um artifício bastante comum nas narrativas policiais. A outra personagem de Machen que encarna o detetive amador é Villiers, de $O$ Grande Deus Pã (1894), que será analisada ulteriormente.

Em A Luz Interior, Dyson é um cidadão comum que, após passar por grandes dificuldades financeiras, recebe inesperadamente uma herança que lhe permite estabelecer-se como escritor. Como ele mesmo diz, "sou um homem de letras, mas, talvez, o mais correto seja dizer que sou um homem da ciência" (MACHEN, 2017, p.36). No entanto, ele também afirma ser um homem do mundo, "uma espécie de ocioso da cidade" (MACHEN, 2017, p.36), cuja observação diária de Londres e das pessoas o tornou quem é: um especialista da vida londrina. Ao contrário de outros detetives ficcionais, como Sherlock Holmes, Dyson não dispensa a possibilidade da existência de entidades sobrenaturais atuando no mundo real. Enquanto Holmes racionaliza o possível fantasma sobrenatural em Os Cães de Baskerville (1902), Dyson segue o caminho contrário, afirmando a presença do sobrenatural e rejeitando qualquer explicação racional ou científica para os eventos insólitos.

Nessa narrativa, Dyson se encontra por acaso com um amigo, Salisbury, e, enquanto conversam, compartilha sua opinião sobre o 
fato de Londres ter crimes interessantes e artísticos, porém critica a forma como são mal relatados pelo jornalismo.

Nosso repórter do dia a dia não tem imaginação. Ele estraga a história simplesmente ao contá-la. A ideia que ele faz do horror e do que provoca horror é, lamentavelmente, deficiente. Nada satisfaz o sujeito senão sangue, o sangue vulgar, e, quando consegue alguém desse sangue, ele carrega a mão nas palavras e pensa que está escrevendo a matéria do ano. É uma visão pobre das coisas. (MACHEN, 2017, p.37)

Essa passagem do texto demonstra que as histórias dos crimes circulavam nos jornais e atraíam leitores que queriam saciar sua curiosidade com relatos de assassinatos brutais. Entretanto, Dyson acredita que, por não serem banhadas a sangue, nem sempre as histórias mais interessantes chegam aos jornais, citando como exemplo o caso Harlesden, um subúrbio distante onde outrora moravam o Dr. Black e sua bela esposa Agnes.

Assim que mudaram para o local, o casal era visto pelos vizinhos em passeios ao cair da tarde, porém, subitamente, a esposa não foi mais vista. A princípio, o médico dizia que andava indisposta, mas, com a constância dessa ausência, logo os vizinhos começaram a suspeitar de algo e a murmurar que Agnes estava morta. Entretanto, Dyson se recordava de um estranho episódio, quando, um dia, caminhando pela pradaria que ficava atrás das casas, vislumbrara a figura de uma mulher na casa do Dr. Black. A visão fora acompanhada de um choque na espinha e do ranger de seus dentes, acometido que fora de uma incontrolável sensação de terror. A face da mulher era humana, mas havia nela algo de 
sobrenatural. Na época, Dyson procurara convencer-se de que tinha sido uma ilusão.

Algum tempo depois, Dyson lera nos jornais uma notícia intitulada "O caso Harlesden", que se reportava à morte de Agnes Black. A causa mortis, segundo os legistas, fora uma estranha doença que causara mutações no cérebro da mulher a tal ponto que não se assemelhava mais a um cérebro humano. A curiosidade faz com que Dyson decida investigar as circunstâncias da misteriosa morte da Sra. Black, conforme afirma em sua conversa com Salisbury: "Esse é o caso Harlesden, Salisbury, e eu acredito que ele me interessou porque não há a mais leve possibilidade de eu ou quem quer que seja possa descobrir alguma coisa a respeito dele" (MACHEN, 2017, p.52).

Cabe, no entanto, a Salisbury fornecer a Dyson, que encarna o papel do detetive, as pistas de que este necessita. Ao presenciar uma briga de casal no meio da rua, Salisbury vê quando a mulher joga ao chão um papel amassado, ele o recolhe e lê as seguintes palavras: " $Q$ teve que visitar seus amigos em Paris. Travers Handle S. Uma vez ao redor da grama, duas vezes ao redor da menina, três vezes ao redor do bordo". Mesmo considerando a mensagem uma tolice, ele não se desfaz do papel e menciona o fato em seu próximo encontro com Dyson, que, aficionado às investigações, promete tentar descobrir algo a respeito.

Em uma de suas caminhadas pela cidade, Dyson vê-se defronte a uma lojinha cujo nome é Travers e só então se dá conta de que está em Handle Street. Decide entrar na loja e, por brincadeira, repete para o atendente as palavras que estavam no bilhete. Em 
resposta, este lhe entrega um pacote, que contém uma belíssima pedra opala e um livrinho, que pertencera ao Dr. Black. Ao ler o relato deste, contido no livrinho, Dyson acaba descobrindo a verdade terrível por trás da morte da Sra. Black, que perdeu sua humanidade quando uma entidade entrou em seu corpo e a transformou completamente. A essência humana da Sra. Black foi colocada na opala, que Dyson prontamente destrói em um acesso de horror ao perceber do que se tratava o objeto.

Dyson colocou o livrinho sobre a mesa, voltouse e olhou, de novo, para a opala com sua flamejante luz interior e, então, com indizível horror emergindo de seu coração, pegou a joia, jogou-a no chão e esmagou-a com os pés. Sua face estava pálida de horror quando ele se virou e, por um momento, ficou de pé, enjoado e tremendo. Então, assustado, atravessou o cômodo e encostou-se à porta. Houve um sibilar ameaçador, como se gás escapando sob elevada pressão e, quando ele olhou, imóvel, o enorme volume de uma fumaça amarela estava saindo do centro da joia e retorcendo-se, como uma cobra, sobre ela. Então, uma pequena chama branca saiu da fumaça, disparou para o ar e desaparece. No chão, ficaram mil pequenos pedaços escuros, como vidro. (MACHEN, 2017, p.59)

O Dr. Black era o único que sabia o que de fato havia acontecido com Agnes, porém, após a sua morte, Dyson, se torna o único personagem na narrativa a conhecer esse terrível segredo.

Em A Mão Vermelha, acompanhado pelo seu amigo cético Phillipps, Dyson decide investigar a morte repentina de Sir Thomas Vivian, um médico conhecido, que foi encontrado morto em um 
beco escuro, com um bilhete dentro de seu bolso. Próximo ao cadáver, havia um muro com o desenho de uma mão em figa.

Dyson diz a Phillips que possui a cópia desse bilhete graças ao inspetor Cleeve, responsável pelo caso, que gosta de estimular sua "curiosidade de amador que investiga mistérios" (MACHEN, 2017, p.70). Como na obra anterior, Dyson investiga o assassinato de Sir Vivian pelo simples prazer de desvendá-lo, principalmente ao desconfiar de uma possível relação com o sobrenatural. "Dyson mantinha-se envolvido com a linha de pesquisa que traçara para si mesmo. A curiosidade intensa e o prazer inato pelo obscuro eram, por si sós, grandes incentivos" (MACHEN, 2017, p.71).

Além de sorte e coincidência fazerem parte do processo de resolução do crime para Dyson, já que ele recebe de Phillips uma pedra escura e antiga marcada com caracteres semelhantes à escrita cuneiforme e com um papel grudado na parte de trás que o auxilia a descobrir o assassino de Sir Vivian, ele também conta com sua inteligência aguçada, pois, ao analisar o objeto, rapidamente encontra as respostas que precisa: "quando Dyson olhou com mais atenção, ele pôde ver marcas de lápis e, ansioso, pegou a lupa para examinar melhor o pedaço de papel. [...] em um instante, a solução se apresentou a ele, fazendo-o rir de satisfação" (MACHEN, 2017, p.75).

Após analisar o papel, Dyson arquiteta um plano com um artista de rua para que desenhe uma mão em figa todos os dias na calçada do Museu Britânico e fica observando de sua casa as pessoas que passam em frente ao desenho. Ele afirma estar colocando em ação a teoria da improbabilidade, "o único princípio científico que eu conheço que permite a alguém encontrar uma pessoa desconhecida em meio a cinco milhões" (MACHEN, 2017, 
p.78). A teoria o faz chegar até o Sr. Selby, amigo e assassino de Sir Vivian, e Dyson sabe que ele é o culpado por ter sido o único que demonstrou desespero ao ver a mão desenhada no chão.

Dyson o confronta em relação ao crime, que é confessado, e Sr. Selby demonstra curiosidade em saber como o detetive amador o encontrou, já que havia enigmas e códigos envolvidos na comunicação entre Selby e Sir Vivian. Dyson começa a explicar seu raciocínio afirmando que rejeita "qualquer crédito por sagacidade, já que cometi erros crassos" (MACHEN, 2017, p.84). Ele admite que o bilhete encontrado no bolso do Sir Vivian não demorou muito para ser decifrado.

Logo percebi que os termos de astronomia substituíam palavras e frases comuns. Você perdeu alguma coisa preta, ou alguma coisa preta tinha sido roubada de você; o globo celestial é uma cópia do céu, então, ficou claro que você tinha uma cópia do que perdeu. Obviamente, cheguei à conclusão de que você tinha perdido um objeto preto com caracteres ou símbolos escritos ou gravados neles, uma vez que o objeto em questão, certamente, tinha informações valiosas, e todas as informações importantes devem ter cópias bem guardadas. 'Nossa velha órbita permanece imutável', significa nosso velho caminho ou acordo. 'O número do meu signo' significava 'o número de minha casa', em alusão aos signos do zodíaco. Não preciso dizer que 'o outro lado da lua' só podia significar um lugar aonde ninguém ainda tinha ido, e 'alguma outra casa' indicava outro lugar para encontro, 'casa', aí, era um termo antigo para 'casa dos céus'. Então, meu próximo passo foi encontrar o 'céu preto' que tinha sido roubado e, por um processo um tanto demorado, acabei encontrando. (MACHEN, 2017, p.84-85) 
E Dyson continua explicando como sua linha de raciocínio o levou até Selby, que admite serem "admiráveis" as conclusões do detetive amador. Mesmo solucionando o caso intrigante da morte de Sir Vivian e encontrando o assassino, Dyson não o entrega à polícia, pois Selby mostra um objeto antigo que horroriza tanto Dyson quanto Phillipps, provando que ainda existem os guardiões do tesouro que ele procurava, uma raça antiga que mora sob a colina: "'os guardiões ainda estão lá, e eu os vi, e por causa disso aqui', e tirou do bolso um pequeno e curioso objeto trabalhado em ouro. - Eis aqui. - disse ele. - Isto é a Dor do Demônio"16 (MACHEN, 2017, p.86). Selby recebe de volta a pedra negra que Phillipps encontrara por acaso e fora fundamental para a resolução do crime e vai embora sem nenhum impedimento.

Em A Pirâmide Reluzente, Dyson é chamado pelo seu amigo, Sr. Vaughan, para investigar acontecimentos estranhos que estão ocorrendo em seu quintal que podem culminar em um futuro roubo à sua casa. Ao chegar ao local e observar os arredores com atenção, Dyson encontra o desenho de um olho feito no muro da casa do Sr. Vaughan e sugere ter sido produzido pelas crianças da região, explicando que a altura do desenho indica essa possibilidade.

- Ora, veja a altura. Esses tijolos têm pouco mais de cinco centímetros de altura e, do chão até o desenho são vinte fileiras de tijolos, o que nos dá pouco mais de um metro de distância. Agora, imagine que você terá que fazer um desenho no muro. Seu lápis, se estiver usando um, tocaria no muro aproximadamente na altura de seus olhos, ou seja, pouco mais de um metro e vinte centímetros

16 Do original em inglês: Pain of the Goat. 
do chão. Então, é razoável supor que este olho na parede foi desenhado por uma criança de mais ou menos dez anos de idade. [...] Ainda assim, há alguma coisa que não é própria de uma criança nestas duas linhas e no próprio olho. Veja, é quase oval. Para mim, esta coisa tem um ar estranho, antigo e uma aparência desagradável. Não posso deixar de imaginar que, se virmos toda a face desenhada pela mesma mão, ela também seria bem desagradável. Mas, isso é bobagem! Afinal, não estamos avançando em nossa investigação. (MACHEN, 2017, p.97)

No entanto, Dyson não consegue organizar de forma satisfatória todas as evidências encontradas na casa, sentindo-se frustrado e tentado a voltar para Londres. "Dyson estava inclinado, no princípio, a manobras detetivescas, mas a simples observação acurada convenceu-o da impossibilidade da hipótese do roubo e ele pôs-se a procurar alguma teoria mais satisfatória" (MACHEN, 2017, p.98). Assim, continuando a pensar insistentemente sobre o caso e a percorrer novamente a propriedade do amigo, Dyson encontra no dia seguinte outro olho desenhado no muro do quintal. Isso faz o dono da casa questionar quem poderia ser o autor, já que perceberam não ter sido produzido pelas crianças.

- Acho que o próprio diabo está envolvido! - disse Dyson. - É claro que não é difícil chegar à conclusão de que esses olhos amendoados infernais tenham sido desenhados pela mesma pessoa que arrumou as pedras pontiagudas. Agora, aonde essa conclusão pode nos levar é mais do que posso supor. No que me diz respeito, tenho que colocar um freio na minha imaginação ou ela vai inventar loucuras. (MACHEN, 2017, p.98) 
Entretanto, sendo Dyson sensível ao mundo sobrenatural, não descarta a chance de seres míticos habitarem as colinas perto da casa do amigo e sai à procura de provas concretas ao invés de se basear apenas em suposições. Depois de seis dias, Dyson leva Sr. Vaughan para uma caminhada noturna até uma das colinas cujo terreno era formado por "uma depressão circular que devia ter sido um anfiteatro romano, cercado por formações de calcário como se fosse um muro semidestruído" (MACHEN, 2017, p.101). O possível encontro com seres sobrenaturais para Dyson não é visto como algo irracional ou uma brincadeira. Ele avisa ao amigo que "A menos que eu esteja muito errado, encontraremos uma explicação séria para o quebra-cabeça" (2017, p.102). E, como Dyson estava correto, os dois são testemunhas de um sacrifício ritualístico de uma jovem que havia desaparecido na região, realizado por uma raça antiga chamada de "Povo Pequeno". A colina onde acontece o ritual se inflama, dando a impressão de ser uma pirâmide reluzente.

No dia seguinte, apesar de relutar muito, Sr. Vaughan aceita que Dyson explique o que os dois testemunharam e como ele chegou a essa conclusão terrível, e o detetive amador começa a narrar todo seu processo mental até chegar ao fatídico dia:

Não há necessidade de repetir a narrativa das pedras. No começo, achei algo trivial, talvez brincadeira de crianças, mas, quando você me mostrou a ponta da flecha, isso aguçou meu interesse. Percebi que aquele fato estava longe de ser lugar-comum, era um assunto realmente curioso e, logo que cheguei aqui, dispus-me a encontrar uma solução [...]. Sua teoria de possível planejamento para roubar sua prataria eu considerei, logo, logo, insustentável, e admito que fiquei perdido na hora de elaborar uma 
hipótese possível. Mas o que me colocou na pista foi mera casualidade. (MACHEN, 2017, p.106-107)

Dyson continua explicando que conseguiu unir a história do desaparecimento da jovem aos desenhos no muro e às pedras organizadas no caminho atrás do quintal da residência e que todos os três mistérios eram produto de um mesmo feitor: o Povo Pequeno. O detetive relata que se lembrou de lendas contadas antigamente na região sobre a existência de um povo pequeno que morava ali, também chamado de "fadas", e de como os moradores locais haviam espalhado rumores de que a jovem desaparecida teria sido levada por eles. Suas suspeitas se confirmam quando presenciam o ritual da pirâmide de fogo.

Nas obras analisadas em que Dyson está presente, suas investigações o levam à resolução do mistério, porém, em nenhuma delas, ele faz justiça com as próprias mãos ou leva o caso às autoridades legais. Dyson apenas apresenta a solução e sacia sua curiosidade em relação a conhecimentos sobrenaturais, diferentemente de Villiers, personagem que atua como o detetive amador em $O$ Grande Deus Pã. Movido primeiramente por curiosidade, depois por desejo de justiça pessoal, Villiers se torna o responsável por investigar os mistérios que inquietam os homens aristocratas da sociedade londrina após uma série de suicídios inesperados acontecerem.

Villiers é apresentado ao leitor no terceiro capítulo da novela, quando, inesperadamente, reencontra um colega da época de faculdade, Charles Herbert, que está em situação de miséria extrema por causa de sua esposa, uma jovem belíssima, chamada Helen. Charles narra seus infortúnios e confidencia a 
Villiers que a esposa o corrompera de corpo e alma. Este se sente intrigado diante dos fatos narrados, como é possível observar na passagem a seguir:

Villiers refletiu bastante sobre a história que lhe fora contada e imaginou se ele tinha ouvido tanto o começo quanto o fim. "Não", pensou, "com certeza não ouvi o final, só o início. Uma história como essa é como aquelas caixas chinesas, você abre uma, depois outra e outra e encontra alguma coisa bizarra em cada caixa. É bem provável que Herbert tenha sido uma dessas caixas, e deve haver outras mais estranhas". (MACHEN, 2017, p.224)

Mais tarde, quando Villiers se encontra com Austin, um amigo "que era famoso por conhecer a vida londrina como ninguém, tanto o lado brilhante como o tenebroso" (MACHEN, 2017, p.224), e questiona-o sobre Herbert, descobre que este tivera a vida totalmente transformada desde que um cavalheiro aparecera morto em frente à sua casa, na Paul Street. Segundo Austin, a polícia nunca foi capaz de solucionar o caso. Villiers acha a história extraordinária e decide investigar sozinho a casa em que Herbert morava com a esposa no dia desse incidente. Após a investigação, Villiers procura Clarke, a quem pede ajuda para solucionar o mistério em relação a Herbert e sua esposa, alegando ter se sentido muito incomodado no local. Villiers acredita que há algo mais a ser descoberto, especialmente depois de ter lido no jornal que Herbert havia falecido. Clarke responde que apesar de todas as peculiaridades, "é concebível que o caso possa ser explicado de maneira mais racional" (MACHEN, 2017, p.230), tendo em vista que Villiers "estava às voltas com suas fantasias sombrias" (MACHEN, 2017, p.230). 
A tentativa de Clarke em racionalizar as "fantasias" de Villiers não diminui seu interesse em continuar investigando a história de Herbert e este decide que seu próximo passo será encontrar Helen: "Pretendo procurar aquela mulher, aquela com quem ele casou. Ela é o mistério" (MACHEN, 2017, p.230 - grifo do autor). Ele pede ajuda a Clarke nessa tarefa, que promete pensar no assunto, porém envia uma carta negando a colaboração e aconselhando-o a deixar todo esse mistério de lado: "Resolvi, e nada vai alterar minha decisão, não investigar um único instante dessa história e, se você valoriza sua felicidade, deverá fazer o mesmo" (2017, p.233). No entanto, Villiers está obstinado em encontrar uma resposta e recorre à Austin novamente, que concorda com o colega de que há algo extremamente terrível nessa história e afirma que "é impossível chegar à conclusão em um caso como esse" (2017, p.234).

Nesse ínterim, alguns homens da alta sociedade se suicidam, em intervalos pequenos entre uma morte e outra, e isso alarma a população. "Pouco após o último destes terríveis eventos, Austin foi à casa de Villiers. Ele estava curioso para saber se Villiers tivera sucesso na busca por rastros recentes da Sra Herbert, por intermédio de Clarke ou por outras fontes" (MACHEN, 2017, p.240). Villiers nega, dizendo que Clarke se recusou a cooperar e, apesar de ter usado outros canais, não obteve sucesso e não conseguiu descobrir o que aconteceu com Helen após ter se mudado da Paul Street.

Mais um suicídio é anunciado enquanto Austin e Villiers conversam e, por coincidência, Villiers havia visto o cavalheiro saindo da casa de uma dama, Sra. Beaumont, recém-chegada à cidade, mas que foi bem recebida socialmente por sempre organizar 
eventos interessantes para a elite londrina. O cavalheiro avistado por Villiers estava visivelmente transtornado ao sair da casa da Sra. Beaumont e, segundo o detetive amador, "[...] aquele homem não pertencia mais a este mundo, eu estava olhando para o rosto de um demônio" (MACHEN, 2017, p.245).

Villiers decide investigar também a Sra. Beaumont quando percebe que os cavalheiros que se suicidaram de alguma forma tiveram contato com ela momentos antes de tirarem a própria vida: "Vou ser se consigo descobrir alguma coisa a respeito da casa por meio de algumas pessoas que eu conheço e, se eu descobrir alguma coisa, aviso a você" (2017, p.245).

Após três semanas de investigação, Villiers descobre que a Sra. Beaumont na verdade é Helen, ex-esposa de Herbert. Ele confessa tê-la visto em um lugar no qual ninguém jamais esperaria encontrar uma dama que mora na Ashley Street, em Picadilly: "Vi-a entrar em uma casa numa das ruas mais sórdidas e de mais má-fama no Soho" (2017, p.246).

A fim de buscar respostas para seus questionamentos, Villiers percorre a cidade de Londres, que conhece muito bem, se embrenhando em becos escuros e vizinhanças sombrias: "Fui a muitos lugares estranhos. [...] Ora, presumindo, como eu acreditava, que a ficha dela não era das mais limpas, eu estava certo de que, em algum momento, ela tinha circulado por meios não tão refinados como os que hoje frequenta" (2017, p.246). Os moradores dos subúrbios sórdidos conhecem Villiers e o auxiliam prontamente por saberem que ele não tem nenhum tipo de ligação com a Scotland Yard. E, assim, ele fica sabendo da história de Helen, 
que morou ali por alguns anos com o sobrenome Raymond e fez coisas inomináveis até mesmo para os habitantes do lugar.

No entanto, somente depois de decidir seguir disfarçadamente a Sra. Beaumont pela cidade, Villiers começa a fazer a conexão entre todas as histórias que ouviu até então. "Senti alguma coisa estranha quando ela entrou na Ashley Street e a ideia de que a Sra Herbert poderia ser a Srạ Beaumont veio-me à mente pela primeira vez, embora parecesse improvável demais para ser verdade" (MACHEN, 2017, p.248). Ao questionar um colega seu, que também estava por perto, sobre a identidade da mulher que ele seguia, fingindo não conhecê-la, Villiers percebe que "não poderia haver nenhuma dúvida a respeito" (2017, p.248), a Srạ Herbert e a Srá Beaumont são realmente a mesma pessoa.

Villiers narra sua jornada investigativa a Austin e mostra que encontrou ainda mais informações sobre a moça por meio de um manuscrito relatando os divertimentos proporcionados pela $\mathrm{Sr}^{a}$ a Beaumont a alguns de seus convidados. Assim, Villiers descobre que Helen organizava orgias em culto ao deus Pã em sua casa e que os homens que participavam do evento, não conseguindo suportar o horror causado pelos próprios atos, suicidavam-se. Decidido a pôr um fim na série de suicídios, Villiers conta que comprou uma corda e irá até a casa de Helen com Clarke para confrontá-la a respeito de tudo. "Vou oferecer a ela a possibilidade de escolher. Vou deixar Helen Vaughan com esta corda em um quarto fechado à chave por 15 minutos. Se, quando entrarmos, ela não tiver feito o que esperamos, vou chamar o policial mais próximo. Vai ser assim" (MACHEN, 2017, p.250-251). No último capítulo, o leitor descobre que Helen, de fato, se enforcara. 
Dessa forma, o resultado final da investigação de Villiers provoca uma ação mais voltada para justiça pessoal, especialmente porque dois colegas seus foram vítimas de Helen, do que um processo judicial realizado por autoridades legais, que mal aparecem na narrativa e são usadas como último recurso, talvez por não serem capazes de solucionar um caso tão complexo como esse. Com isso, entendemos que apesar de Villiers não receber completamente todas as informações sobre Helen, deixando que outros personagens, como Austin e Clarke, contribuíssem para completar o quebra-cabeça, isso não o impede de ser o único que insiste em investigar a fundo os eventos sinistros ligados à jovem.

\section{CONSIDERAÇÕES FINAIS}

Para Carla Portilho (2009, p.62), "o detetive do século XIX simbolizava a fé da época nas habilidades do homem para resolver os problemas do mundo", mas também "a crescente desilusão do homem quanto à razão como uma resposta significativa para a condição humana". Nesse sentido, é possível dizer que os detetives de Arthur Machen refletem bem o Zeitgeist, pois a capacidade investigativa das personagens é entrelaçada à presença do sobrenatural. Apesar de ficarem abalados e horrorizados com as informações que vão obtendo ao longo das narrativas, Villiers e Dyson não perdem nem a sanidade nem a vida. Isso mostra que, por exercerem o papel de detetives amadores, eles estão imunes às ameaças e consequências do encontro com o mal sobrenatural, pois eles são necessários para a resolução da história.

Diferentemente de detetives como Dupin e Sherlock Holmes, Dyson e Villiers não possuem um ajudante que narra os 
extraordinários processos investigativos que levam os detetives a solucionarem os mistérios. A função do ajudante narrador é fazer a ponte entre o detetive e o público, pois é por meio dele que a explicação do raciocínio investigativo chega ao leitor. Na ficção de Machen, entretanto, são os próprios personagens detetives que relatam como obtiveram sucesso na conclusão do caso, muitas vezes deparando-se com coincidências ou encontros inesperados. Sage Leslie-McCarthy explica que o acaso é uma parte importante nas obras iniciais de Machen, especialmente para as investigações, pois os personagens detetives

se deparam com um mistério por acidente e o investigam como resultado de curiosidade. No processo, eles demonstram a importância de olhar não apenas para as pistas materiais, mas também para abaixo da superfície das realidades da cidade, a fim de entender a verdade mais profunda, que é revelada através de coincidência e encontros fortuitos. ${ }^{17}$ (2008, p. 37 - tradução nossa)

Levando em consideração que "cada tipo de detetive deve suas características ao momento histórico em que foi criado e à sociedade em que está imerso" (PORTILHO, 2009, p.15), Dyson e Villiers seriam homens voltados à razão, mas que não ignoram o fato de o sobrenatural existir e não se amedrontam diante dele, indo até onde lhes é possível para que uma solução seja encontrada e, no caso particular de Villiers, a justiça seja feita, mesmo que por meios não oficiais.

17 "[...] come across a mystery by accident and investigate it as a result of curiosity. In the process they demonstrate the importance of looking not only at material clues but also below the surface of realities of the city in order to understand the deeper truth, which is revealed through coincidence and chance encounters" (LESLIE-MCCARTHY, 2008, p.37). 
Finalmente, Dyson e Villiers são figuras que se assemelham ao flâneur, pois ambos são observadores tanto da cidade quanto dos moradores dela, conhecendo desde os locais de moradia da elite até os piores subúrbios. "Como 'detetives', eles se tornam ativamente envolvidos em entender e interpretar eventos que ocorrem em seu ambiente, um fator que os liga à figura do explorador social"18 (LESLIE-MCCARTHY, 2008, p.38 - tradução nossa). Sendo assim, ambas as personagens representam o detetive amador entusiasta por conhecimento que se engaja em especulações metafísicas e, às vezes, em cenários góticos (PYCKETT, 2003, p.5) e que, apesar de não saber conduzir investigações oficiais, consegue encontrar informações suficientes para desvendar o mistério e sanar sua curiosidade pelo conhecimento que está além do alcance dos homens comuns.

\section{REFERÊNCIAS}

ADLER, Emily (2020). Weird Fiction and Science at the Fin de Siècle. Edinburgh, UK: Palgrave Macmillan.

GRELLA, George (1970). "Murder and Manners: The Formal Detective Novel". NOVEL: A Forum on Fiction, 4(1), 30-48.

KAYMAN, Martin A. (2003). "The short story from Poe to Chesterton". In: The Cambridge Companion to Crime Fiction. New York: Cambridge University Press, p.41-58.

KNIGHT, Stephen Thomas (2004). Crime Fiction, 1800-2000: detection, death, diversity. New York: Palgrave Macmillan.

LESLIE-MCCARTHY, Sage (2008). "Chance Encounters: The Detective as 'Expert' in Arthur Machen's The Great God Pan". Australasian Journal of Victorian Studies, Sydney, 13(1), 35-45. In https://openjournals.library. sydney.edu.au/ index.php/ AJVS/article/view/9331/9230 Acesso em 4.Mai.2019.

18 "As 'detectives' they become actively involved in understanding and interpreting events that occur in their environment, a factor that links them to the figure of the social explorer" (LESLIE-MCCARTHY, 2008, p.38). 
MACHEN, Arthur (2017). "A Luz Interior". In: - Arthur Machen: o mestre do oculto. Jundiaí: Editora Clock Tower. p.35-59. (2017). "A Mão Vermelha”. In: Arthur Machen: o mestre do oculto. Jundiaí: Editora Clock Tower. p.61-87. (2017). "A Pirâmide Reluzente". In: . Arthur Machen: o mestre do oculto. Jundiaí: Editora Clock Tower. p.89-109. (2017). "O Grande Deus Pã". In: - Arthur Machen: o mestre do oculto. Jundiaí: Editora Clock Tower. p.209-256.

PORTILHO, Carla de Figueiredo (2009). Detetives ex-cêntricos: um estudo do romance policial produzido nas margens. (Tese - Doutorado em Letras). Universidade Federal Fluminense, Niterói.

PRIESTMAN, Martin (2003). "Introduction: crime fiction and detective fiction". In: (Ed.). The Cambridge Companion to Crime Fiction. Nova York: Cambridge University Press. p.1-17.

PYKETT, Lynn (2003). "The Newgate novel and sensation fiction, 1830-1868". In: PRIESTMAN, Martin (Ed.). The Cambridge Companion to Crime Fiction. New York: Cambridge University Press. p.19-39.

TODOROV, Tzvetan (2003). As Estruturas Narrativas. São Paulo: Perspectiva. WORTHINGTON, Heather (2010). "From The Newgate Calendar to Sherlock Holmes". In: RZEPKA, Charles J.; HORSLEY, Lee (Eds.). A Companion to Crime Fiction. Singapura: Wiley-Blackwell, p.13-27. 